\title{
PHILOLOGY
}

\section{ОСОБЕННОСТИ ГАЗЕТНОГО СТИЛЯ И ГАЗЕТНЫХ ЗАГОЛОВКОВ В ГРУЗИНСКОМ И АНГЛИЙСКОМ ЯЗЫКАХ}

\author{
Тамила Кемаловна Дилаверова \\ Батумский международный университет, Грузия \\ DOI: https://doi.org/ 10.31435/rsglobal_ws/30092018/6141
}

\section{ARTICLE INFO}

Received: 27 July 2018

Accepted: 25 September 2018

Published: 30 September 2018

\section{KEYWORDS}

newspaper headline,

journalism,

peculiarities,

publicistic style.

\begin{abstract}
Political changes, occuring in any country, are directly related to the media, which, in turn, is responsible for the reliability of the disseminated information. Any text or article requires an appropriate heading. Publicistic headings, in comparison with artistic ones, are more informative and diverse, and their author should consider many factors, affecting them. A good heading should reveal the essence of the text as much as possible, and it should arouse a reader's interest as well. The paper also deals with the peculiarities of a newspaper text and a newspaper heading, which should be analyzed for a critical approach to the study of the researched object.
\end{abstract}

Citation: Тамила Кемаловна Дилаверова. (2018) Osobennosti Gazetnogo Stilya i Gazetnih Zagolovkov v Gruzinskom i Angliiskom Yazikah. World Science. 9(37). doi: 10.31435/rsglobal_ws/30092018/6141

Copyright: () 2018 Тамила Кемаловна Дилаверова. This is an open-access article distributed under the terms of the Creative Commons Attribution License (CC BY). The use, distribution or reproduction in other forums is permitted, provided the original author(s) or licensor are credited and that the original publication in this journal is cited, in accordance with accepted academic practice. No use, distribution or reproduction is permitted which does not comply with these terms.

Основные изменения, произошедшие в XX веке, были обусловлены ролью и ростом влияния средств массовой информации. Сегодня пресса, телевидение и интернет являются неотъемлемой частью современного мира, и, что самое главное, они оказывают огромное влияние на жизнь людей. В этом плане наибольший интерес представляет изучение газетного стиля, который является одним из довольно новых и глубоко прагматических вопросов публицистики.

Газетно-публицистический стиль - один из самых популярных типов публицистического стиля, который в силу своего предназначения, задач и условий общения представляет достаточно сложное явление и полностью обусловлен особенностями экстралингвистических аспектов. Публицистические тексты направлены на информирование граждан о новых событиях, фактах и достижениях в культуре, науке или технике, происходящих в общественной жизни; на предоставление объективного развития событий и формирование общественного мнения в желаемом направлении; на заинтересованность граждан и побуждение к деятельности; на поощрение социальных процессов. Коммуникационная функция в публицистическом стиле, в отличие от научной, имеет свои методы и способы распространения информации. Содержание публицистического стиля определяется разнообразной тематикой, связанной с различными областями жизни, целями и устремлениями (Цинцадзе, 2016, 11-12).

Как уже упоминалось, газетный стиль является особенным и отличающимся, и, следовательно, принцип выбора заголовка также требует особого подхода.

Роль заголовка в прессе очень важна, так как понимание текста в некоторой степени зависит от того, как заголовок влияет на представление текста. Заголовок является существенным элементом статьи, он в первую очередь привлекает внимание читателя. Заголовок осуществляет функцию так называемого посредника между текстом и читателем. А отдельно взятый заголовок полностью заменяет текст с прагматической точки зрения. Именно заголовок представляет собой тот элемент, который первым привлекает внимание рецептора. 
Функция заголовка состоит в том, чтобы подготовить и подвести читателя к тексту. Для этого авторы прибегают к различным методам.

Каким же должен быть хороший заголовок? - оригинальным, смешным, креативным, он должен рассказывать о тексте и, в то же время, не передавать всего содержания, оставлять интригу. Другими словами, заголовки также разнообразны, как и их авторы.

Так называемые «говорящие» заголовки создают первичное представление о публикации, таким образом, читатель сам решает, что ему читать первым делом, а что отложить на потом.

По существу, заголовок имеет две задачи. В одном случае, он должен помочь отличить одно произведение от другого, идентифицировать предмет, как независимую единицу. В это время номинация касается больше внешней стороны. Она не имеет целью указывать на суть названного, раскрывать его внутреннюю глубину.

Во втором случае, заголовок является составным элементом, своеобразным ключом, который должен облегчить нам проникновение в лабиринт творчества. Он должен указывать не только на тему произведения, но и на авторскую позицию, на сам по себе жанр, а также должен заинтересовать и привлечь аудиторию (Талиашвили, 2012 год, 4).

Журналистский заголовок - это предтекстовый индикатор текста, сигнал текста. Он формально отделяется от основного текста, одновременно представляет собой часть целого и независимое сообщение. Таким образом, он является единицей, образованной от текста, а также самим текстом.

Наблюдения за заголовками современных журналов и газет показали, что на первом плане сейчас находится функция рекламы, однако акцентирование на этой функции не всегда означает хорошо подобранный заголовок. Существует несколько групп заголовков, которые условно можно назвать рекламными или интригующими. Условно - потому, что интрига является лишь мотивом для их создания. На самом деле, они не могут достичь цели, они не привлекают внимания читателя. (Палавандишвили, 2014: 32)

В грузинских СМИ лаконизм заголовка сменила противоположная тенденция: короткие заголовки заменили длинные и сложные языковые конструкции. В первой группе мы объединили те длинные заголовки, которые не только не привлекают внимания читателя из-за излишка информации, но и отрезают ему путь к тексту. Приведем несколько примеров:

„sapatriarko ar adasturebs inpormatsias, rom Ilia II sochshi visits apirebs“ (Патриархия не подтверждает информацию о том, что Илья II собирается посетить Сочи); „,iaponiashi birtvui krizisis saprtkhe chernobilis donemde astsies“ (Угрозу ядерного кризиса в Японии вщспринимают на уровне Чернобыля); „Tbilisi sochis olimpiadistvis gagrashi gasartobi tsentrebis msheneblobis aprotestebs“ (Тбилиси протестует против строительства развлекательных центров в Гагре для сочинской Олимпиады); „saertashoriso sasamartlo rusetis tsinaaghmdeg sakartvelos sarchels ar ganikhilavs“ (Международный суд не рассматривает иск Грузии против России»; „utsnobi“ „maestros“ aktsiebis 50\%25-is mplobeli khdeba da akhal shous itskebs“ (Уцноби» присвоил себе $50 \%$ акций «Маэстро» и начинает готовить новое шоу); „bakradzis vizitis gadadeba ebraeli biznesmenebis sakmes ar ukavshirdeba“ (Отмена визита Бакрадзе не связана с делом еврейских бизнесменов); „,klimiashvilis gardatsvalebastan dakavshirebit gamodzieba tvitmkvlelobis versiasats ganikhilavs“ (в отношении расследования убийства Климиашвили следствие также рассматривает версию самоубийства); "evroviziis" konkursi diuseldorpshi im stadionze tardeba, sadats 30 tslis tsin tbilisis „dinamom“ tasebis mplobelta tasi moipova” (Конкурс «Евровидение» проводится в Дюссельдорфе на стадионе, где 30 лет назад Тбилисское «Динамо» выиграл Кубок); «ministrebs mivlinebashi gamgzavreba mkholod premier (-) ministrebs tankhmobis shemdeg sheedzebat» (Министры смогут отправиться в командировку только после согласия премьерминистра) ... Заголовки такого типа настолько объемные, что их можно рассматривать в качестве резюме тех текстов, заголовками которых они являются (Омиадзе-2012: 4).

Отдельную группу составляют те заголовки, в которых настолько неинтересна неизвестная часть информации, что вопрос о соотношении неизвестного и известного даже не рассматривается. Таким образом, нельзя сказать, что такие заголовки являются удачными. Например: „ratom egona musikos jgupis misha saakashvili musikosi da ratom dashorda tamuna museridzes“" (Почему музыкант группы думал, что Миша Саакашвили был музыкантом и почему он расстался с Тамуной Мусеридзе?); „ratom gakves satsoli or natsilad irakli cholokashvilma da misma meughlem“ (Почему Ираклий Чолокашвили и его жена разделили кровать на две части»; (ras zveravda nanuli sarajishvilitelavis bazarshi?““ (Что разведывала Нанули Сараджишвили на рынке Телави?).

Хотя последний тип заголовков главным образом принадлежит желтой прессе, мы нередко находим их и на страницах публично-политических журналов и газет. Следует отметить, что такие заголовки привлекают читателя не своей структурой или семантикой, а упоминанием в заголовке тех лиц, которые представляли для него интерес до прочтения данного заголовка и текста.

„,san-prantsisko betmenis kalakad iktsa leikemiit daavadebuli bavshvebistvis” (СанФранциско стал городом Бэтмена для детей, страдающих лейкемией); «prints harize 
dakortsinebis miukhedavad, megan markli printsesis tituls maints ver miighebs" (Несмотря на брак с принцем Гарри, Меган Маркл не получит титула принцессы).

Давайте проанализируем заголовки современной английской газеты. Наш эмпирический материал собран из таких газет и журналов, как «The Times», «The Guardian ".

По словам знаменитого лингвиста Гальперина, со стилистической точки зрения заголовки современной английской газеты характеризуются некоторыми специфическими особенностями и примерами, которые мы рассмотрим ниже.

С целью экономии пространства в английских заголовках большинство форм пассива и глагольных фраз используются там, где пропущен глагол То Ве для описания событий, происходящих как в прошедшем, так и в настоящем времени.

Например:

The Chief Minister expected to come tomorrow

Two people killed in a drive-by shooting on Friday night

Ten children injured when part of the school roof collapsed

Alien base discovered on dark side of the moon

Однако, следует отметить, что глагол to be не может быть часто пропущен и должен употребляться из-за небольшого размера заголовка и широкой информативности:

London is flooded (источник 11)

Taxes are lowered (источник 12)

A meeting will be held by the company's directors next week.= The company's directors will meet next week.(источник 13)

Кроме форм пассива глагол to be может быть пропущен и в Длительном времени (Continuous Tense):

Trump expecting personal letter from Kim Jong-un as summit date nears

Bavarians wary of new law requiring crosses in all public buildings

Часто случается так, что газетные заголовки начинаются с формы Герундия:

Cutting short Gavin Williamson was the most popular thing I've ever done

Housing Authority Joliet receives funding for new units at Liberty Meadows

Также, в заголовках часто употребляется двоеточие (:), которое отделяет тему заголовка от заявления, сделанного по отношению к графически упомянутому факту.

Например:

Prezident Franklin D. Roosevelt is famous for his statement: the only thing we have to fear is fear itself

President Abraham Lincoln began the Gettysburg Address with the following line: Four score and seven years ago our fathers brought forth, upon this continent, a new nation, conceived in Liberty, and dedicated to the proposition that all men are created equal." источник 21).

В заголовках часто встречаются изменения во времени глагола. Чаще всего вместо длительного и совершенного времени (Continuous and Perfect Tenses) употребляются простые формы.

Например:

FORGOTTEN BROTHER APPEARS $=$ A forgotten brother has appeared (after a long period of time).

PROFESSORS PROTEST PAY CUTS = Professors are protesting pay cuts (at the university)

Swedish orchestra turns homophobic hate mail into music.

Что касается прошедшего неопределенного времени (Past Simple Tense), то оно указывает на такие события, которые произошли в прошлом, или в том случае, когда читателю известно точное время освещаемого события.

HUSBAND DISAPPEARED 4 YEARS AGO.

Выводы. Анализ изученных материалов показывает, что газетный стиль довольно своеобразен и разнообразен. Также отличительным является и принцип выбора заголовка, обязывающий автора учитывать множество языковых или экстралингвистических факторов. Принципы создания и функционирования грузинских и английских газетных заголовков сильно отличаются друг от друга. Очевидно, что англичане и американцы больше внимания уделяют заголовкам, следовательно, характерные особенности в их заголовках гораздо легче найти, чем в грузинских.

\section{ЛИТЕРАТУРА}

1. Барбакадзе 2012: Барбакадзе Ц. «Прагматика Заголовка», Тбилиси, Грузия.

2. Омиадзе 2012: Омиадзе С. «Семиотика Заголовка», Тбилиси, Грузия.

3. Палавандишвили 2014: Палавандишвили. «Ситуационный критерий (категория) в публицистических текстах», Тбилиси, Грузияю

4. Талиашвили 2012: Талиашвили Т. «Семиотика Заголовка», Тбилиси, Грузия.

5. Цинцадзе 2016: Цинцадзе И. «Стиль современный публицистики», Тбилиси, Грузия. 